\title{
Práticas estratégicas em pequenos supermercados na percepção do consumidor de baixa renda
}

\author{
Strategy as Practice in Small Supermarkets under the Low-Income Consumers Perception
}

Alipio Ramos Veiga-Neto ${ }^{[a]}$, Tereza de Souza ${ }^{[b]}$

[a] Doutor em Psicologia, Professor do Mestrado em Administração da UnP (Universidade Potiguar) Natal/RN - Brasil, email: alipio@veiga.net

[b] Doutora em Administração, Professora do Mestrado em Administração da UnP (Universidade Potiguar) Natal/RN - Brasil, email: terezasouza@unp.br

\section{Resumo}

Objetiva-se com esta pesquisa analisar as estratégias praticadas pelos pequenos supermercados na percepção do consumidor de baixa renda, pois a disputa pelo consumidor de baixa renda não se limita aos grandes supermercados, que dispõem de recursos para planejar e aplicar estratégias variadas, os pequenos e médios supermercados procuram disputar esses consumidores adotando estratégias de forma que sejam percebidos por seus clientes por determinados atributos, diferenciando-se dos grandes concorrentes. Baseado no modelo conceitual da Estratégia como Prática apresentado por Whittington (2006), composto pelos construtos Praxis, Prática e Praticante, empreendeu-se uma pesquisa descritiva em uma amostra de 300 sujeitos pertencentes ao segmento de baixa renda clientes de três supermercados de bairro. Utilizando análise descritiva e estatística multivariada foi possível identificar no construto Praxis três fatores: 1) ações econômicas; 2) ações no microambiente; e 3) ações nos produtos; que explicaram 16 variáveis relacionadas à Escolha da Loja. No construto Prática outros três fatores foram identificados: 1) serviços recebidos; 2) valores econômicos; e 3) vantagem percebida; explicando 12 variáveis relacionadas aos Serviços Oferecidos. Conclui-se que as práticas estratégicas que os consumidores de baixa renda percebem como muito importante para a Escolha da Loja são o atendimento, a entrega em domicilio e a limpeza e organização e dão pouca importância para o tempo de espera nas filas, o prazo pagamento e a qualidade e variedade frios laticínios. Para estratégias relacionadas aos Serviços Oferecidos os sujeitos dão grande importância para a entrega em domicilio, o atendimento e a limpeza da loja, porém dão pouca importância para cartão fidelidade, marcas próprias e empacotador.

Palavras-chave: Estratégia como prática. Estratégia em supermercados. Consumidor de baixa renda. 


\begin{abstract}
The objective of this research was to analyze the strategies practiced by small supermarkets in the perception of low-income consumers. The competition for low-income consumer is not limited to large supermarkets that have the resources to plan and implement various strategies, small and medium sized supermarkets try to attract these consumers adopting strategies perceived by their customers for certain attributes, that differentiate them from larger competitors. Based on the conceptual model of the Strategy as Practice presented by Whittington (2006), composed by constructs Praxis, Practice and Practitioner, a descriptive survey was undertaken in a sample of 300 subjects belonging to the segment of low-income customers from three small supermarkets. Using descriptive and multivariate statistical analysis was possible to identify three factors in the construct Praxis: 1) economic actions, 2) actions on the micro-environment, and 3) actions in the products, which explained 16 variables related to Choose Store. In the Practice construct other three factors were identified: 1) services received, 2) economic values, and 3) perceived advantage, explaining 12 variables related to the Services Offered. The conclusion was that the strategic practices that low-income consumers perceive as very important for the Selection of the Lodge are the care, home delivery, cleaning and organization, and care little for the waiting time in queues, the term of payment and quality and variety of sausages and dairy products. For strategies related to the Services Offered, these subjects attach great importance to home delivery, customer service, and cleanliness of the store, but give little importance to loyalty cards, private brands and packer.
\end{abstract}

Keywords: Strategy as practice. Strategy in supermarkets. Low-income consumer.

\section{Introdução}

A inflação sob controle, a queda no desemprego e a melhoria dos rendimentos dos trabalhadores de baixa renda resultaram no crescimento de seu poder aquisitivo, destinando grande parcela de seus ganhos ao consumo de alimento. Em 2005, a classe C correspondia a $34 \%$ da população brasileira, desta feita "mais de 20 milhões de brasileiros saíram das camadas sociais mais baixas (...) e alcançaram a classe C, a porta de entrada para a sociedade de consumo" (VEJA, 2008, p. 84). Com o crescimento da economia essa nova classe média tornou-se atraente para diversos segmentos da economia e passou a dispor de crédito com prazos mais ampliados e maior poder de consumo.

O comércio alimentício constitui-se no segmento mais representativo das atividades do setor do varejo, chegando a responder por mais de $40 \%$ da taxa desse setor (IBGE/SEI, 2007). Todavia, no meio acadêmico, poucos estudos sobre as classes menos favorecidas, em especial no segmento de supermercados, têm sido desenvolvidos (MONTEIRO; SILVA; LADEIRA, 2008; PARENTE; BARKI; KATO, 2007). No Rio Grande do Norte, de acordo com levantamento do IBGE, que cruzou dados daquela instituição com os da Fundação Getúlio Vargas, as classes D e E englobam cerca de $72 \%$ da população norte-rio-grandense, com renda mensal abaixo de R\$1.000,00 (O POTI, 2005). A capital do Estado, com a população de aproximadamente 750 mil habitantes pode ser vista como uma amostra da realidade da maioria dos Estados brasileiros. Associada a essa concentração urbana a demanda por consumo de alimentos apresenta-se como um mercado atrativo e em expansão. Os supermercados da cidade têm procurado instalar-se em diversas regiões, seja na periferia, onde a população se caracteriza com um poder aquisitivo menor, seja em bairros em que a população tenha maior poder aquisitivo. Além das estratégias relacionadas à localização os supermercados buscam aumentar sua participação no mercado adotando ações estratégicas práticas no sentido de alcançar a preferência na escolha do consumidor.

A disputa pelo consumidor de baixa renda não se limita aos grandes supermercados, que dispõem de equipes qualificadas para planejar e aplicar estratégias variadas baseadas na visão dos recursos que dispõem (estratégias VBR), tais como poder de barganha e oferta de preços baixos, atendimento diferenciado, estacionamento fácil, serviços adicionais, produtos amigos do ambiente, e marca própria. Os pequenos e médios supermercados, que na sua maioria se localizam em bairros mais afastados, procuram disputar esses consumidores adotando estratégias 
como prática (ECP), de forma que sejam percebidos por seus clientes por determinados atributos, diferenciando-se dos grandes concorrentes. Johnson et al. (2007) apresenta a perspectiva de que a estratégia como prática (ECP) pode ser entendida como aquela atividade que as empresas desenvolvem na prática diária, ou seja as microatividades que constroem a estratégia da organização.

A estrutura do mercado consumidor é complexa tanto do ponto de vista do comportamento do consumidor final, quanto da identificação das estratégias desenvolvidas pelas empresas e conhecer as preferências de seus clientes possibilita decidir sobre quais práticas estratégicas oferecem resultados efetivos para alcançar seus objetivos e metas. Assim objetivou-se com esta pesquisa analisar as estratégias praticadas pelos pequenos supermercados na percepção do consumidor de baixa renda.

\section{Referencial teórico}

Supermercados e o consumidor de baixa renda

Qualquer que seja o mercado a entrada de novos atores provoca mudanças tanto no comportamento dos consumidores, como na gestão das empresas que, antes não sentiam a necessidade de inovar, melhorar níveis de qualidade ou mesmo enxugar sua estrutura. Borges (2001) lembra que no segmento dos supermercados pode-se verificar diferenças fundamentais entre as grandes redes e as pequenas lojas. 0 primeiro grupo possui recursos financeiros fartos, possibilitando investimento em treinamento, processos, tecnologia e instalações. Além disso, o fato de pertencerem a uma cadeia de lojas lhes permite grande fluxo de mercadorias e maior poder de negociação (HARCAR et al., 2006).

Contrariando as expectativas de que as grandes redes acabariam com os supermercados de bairro, observa-se o crescimento desses concorrentes menores que se empenham para encontrar estratégias que permitam criar e sustentar vantagem competitiva. Prahalad e Hamel (2005) destacam que esses pequenos empresários empenham-se no dia a dia, às vezes de forma intuitiva, buscando competências essenciais que possam emergir e serem desenvolvidas dentro de suas empresas com características únicas que as diferenciem de seus concorrentes na percepção de seus clientes. Levy e Weitz (2000) citam algumas ações estratégicas, a título de exemplo, como a qualidade nos serviços, por meio de práticas cotidianas como a simpatia, pronto atendimento, preocupação com os detalhes visuais e personalização do atendimento. Nobrega (2009) vai além quando afirma que, para desenvolver estratégias de diferenciação, os pequenos supermercadistas devem desenvolver competências servidoras, ou seja, aproveitando a agilidade e a proximidade que têm com seus clientes, podem adotar como meta transformar de seu negócio em uma organização servidora, na qual sua atividade primeira é servir a seus clientes.

A fim de colocar em prática suas estratégias competitivas, Campolina (2007) lembra que essas estratégias precisam ser adequadas à realidade e ambiente social que a empresa se insere, utilizando para tanto os conhecimentos e experiências adquiridas pela própria empresa no decorrer de sua vida, devendo-se conhecer e considerar os hábitos e costumes de seus consumidores, a cultura de seus colaboradores e a alocação adequada dos recursos financeiros disponíveis. Esses aspectos são mais bem gerenciados quando entendidos sob o enfoque das cinco vantagens competitivas sugeridas por Slack (2002), ou seja, qualidade, atendimento no tempo, confiabilidade, flexibilidade e custo baixo.

A adequação estratégica ao público alvo pressupõe o atendimento de necessidades específicas de cada segmento identificando tanto os aspectos que satisfazem como aqueles que causam descontentamento (NEUBUSER, 2004). O segmento de baixa renda, ainda que com suas especificidades, deve ser administrado da mesma forma que qualquer outro público, considerado que sua satisfação tem relação com a lacuna existente entre o as expectativas e a percepção que os consumidores têm sobre os serviços prestados (MACHADO et al., 2006).

0 consumidor de baixa renda vem aumentando sua presença nas estatísticas de consumo. Hammond e Prahalad, 2004, salientam que individualmente o potencial de compra desse consumidor é pequeno, porém, enquanto segmento o potencial é elevado. Esses autores destacam ainda que se tem verificado elevado crescimento no número de produtos destinados ao consumidor de baixa renda, em especial produtos eletrônicos portáteis, conhecidos por gadgats. Contrariando o que seria esperado, os consumidores de baixa renda tendem a pagar mais pelos produtos adquiridos. Alwit e Donley (1997) destacam que os consumidores de baixa renda realizam compras 
preferencialmente perto de seus lares em pequenos estabelecimentos de bairro que possuem pouco poder de barganha com os fornecedores e, pela dificuldade em realizar compras mensais, tendem a realizar compras com mais frequência em embalagens menores, que costumam ser mais caras.

Vários são os mitos relacionados ao consumidor de baixa renda, tais como não serem fiéis a determinada marca, serem resistentes a novos produtos, terem baixo nível de informação sendo portanto facilmente ludibriáveis e estarem dispostos a pagar apenas por produtos de preços mais baixos, porém são inúmeras as pesquisas que demonstram que esses conceitos não passam de ideias equivocadas (ANDERSON, 2002; PRAHALAD; HAMMOND, 2002; HAMMOND; PRAHALAD, 2004). Segundo esses autores, o comportamento do consumidor de baixa renda deve ser avaliado a partir de um conjunto de variáveis relacionadas a mudanças ocorridas no âmbito das famílias, ao aumento da oferta de crédito bem como à crescente exposição aos meios digitais.

\section{Estratégia como Prática}

Para a visão tradicional o conceito de estratégia é abstrato e está ligado a algo que as empresas possuem, como diversificação, processos de planejamento estratégico, estratégia baseada em recursos. Esses processos podem ser analisadas, ou enquadrados, dentro de escolas de pensamento estratégico, das quais se tem destacado a contribuição de Mintzberg et al. (2000). Para Johnson et al.(2007) e Whittington (2007) na perspectiva da Estratégia como Prática (ECP) a estratégia deve ser entendida como as atividades que as pessoas da organização fazem e o foco da análise concentra-se nas microatividades desenvolvidas na empresa que moldam a estratégia da organização. A Estratégia como Prática procura compreender o que as pessoas da empresa fazem no processo estratégico e como influenciam o resultado desse processo. Para Jarzabkowski e Wilson (2006) as análises relacionadas aos processos estratégicos estão focadas nas relações entre as atividades gerenciais e o contexto da estratégia, por outro lado a ECP tem foco nos gestores, suas rotinas e procedimentos que constroem a estratégia da empresa.

Johnson et al. (2003) enfatizam que os atores do processo estratégico estão envoltos em um ambiente no qual as formas de se agir são socialmente definidas e são parte constituinte do ambiente institucional. Jarzabkowski, Balogun e Seidl (2007) reforçam esse pensamento afirmando que, para se entender os microfenômenos da ECP, deve-se considerar o contexto no qual as pessoas estão inseridas. Whittington (2006) ressalta a importância do estudo da relação entre as atividades dos atores e as estratégias organizacionais, destacando a escassez de pesquisas com esse enfoque. Concluindo, para a ECP a estratégia deve ser entendida como aquilo que os colaboradores de uma empresa fazem no seu dia a dia e não como algo que a organização possua (JARZABKOWSKI, 2003; VAN DE VEN; JOHNSON, 2006; WILSON; JARZABKOWSKI, 2004).

\section{Modelo e variáveis do estudo}

Para Jarzabkowski (2004), analisando a estratégia como prática verifica-se que as ações dos atores da estratégia, ou seja, suas atitudes, seus comportamentos e suas práticas, fazem a estratégia acontecer. Esses processos podem ser entendidos como uma mistura de ação e direção, cujo resultado faz com que a estratégia aconteça. Em Jarzabkowski (2005), assim como em Whittington (2006) encontra-se um modelo composto por três dimensões inter-relacionadas, a praxis, as práticas e os praticantes, no qual, na região em que essas dimensões se sobrepõem, acontece a elaboração da estratégia. A práxis são as ferramentas e fluxos de ações disponíveis na empresa que auxiliam nos processos estratégicos, ou seja, a forma como os praticantes fazem as coisas para que a estratégia

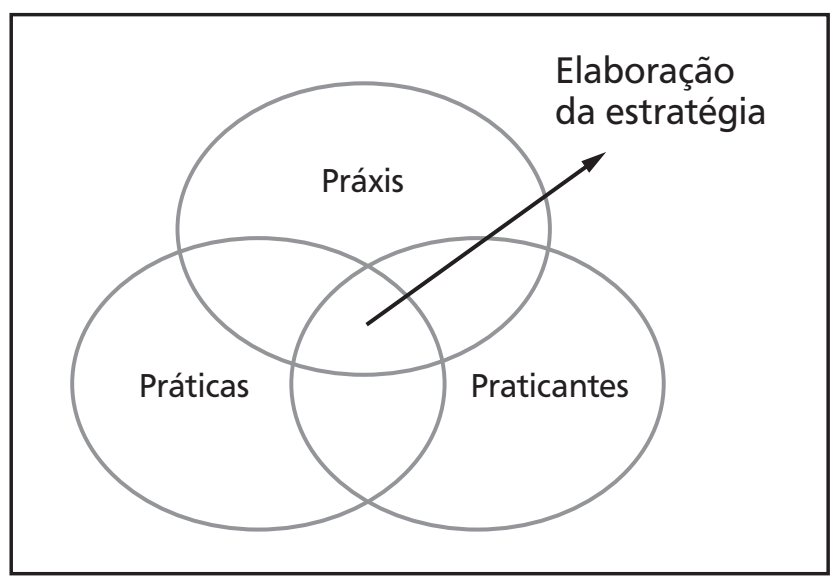

Figura 1 - Modelo conceitual de Whittington

Fonte: adaptado de Jarzabkowski, Balogun e Seidl (2007). 
aconteça. As práticas são as rotinas, procedimentos, comportamentos, motivações e normas socialmente constituídos que são combinadas, coordenadas e adaptadas fazendo parte da cultura organizacional. Finalmente os praticantes são os atores das práticas estratégicas, ou seja aquilo que eles são, como fazem as coisas acontecerem e quais os recursos que usam.

A partir da contribuição de Marietto (2011) consideraram-se dois contructos do modelo de Whittington para a análise das estratégias aplicadas na prática pelos supermercados, a Praxis e as Práticas, uma vez que na percepção dos sujeitos da pesquisa, ou seja, o consumidor, as variáveis relacionadas com o Praticante da estratégia confunde-se com as atividades, ou produtos e serviços oferecidos pela loja. Para Marietto ainda que Praxis e Práticas possuam variáveis que possam confundir-se na percepção do cliente, é possível classificá-las em duas dimensões, aquelas que influenciam na Escolha da Loja, e as que influenciam o consumidor na avaliação dos Serviços Oferecidos (Quadro 1).

\section{Metodologia}

A fim de responder ao objetivo desta investigação optou-se pela utilização de uma pesquisa quantitativa descritiva com aplicação de questionário em pesquisa de campo buscando analisar as variáveis encontradas na literatura. A aplicação da técnica quantitativa foi utilizada em virtude de os dados obtidos na pesquisa contribuírem para a melhor análise estatística e pela confirmação das variáveis encontradas na investigação (MATTAR, 2001).
0 universo pesquisado foi composto por consumidores de baixa renda clientes de 3 (três) supermercados de pequeno e médio porte localizados em bairros de periferia. A amostra foi não probabilística por acessibilidade em que os sujeitos investigados foram selecionados aleatoriamente pela sua disposição em responder ao instrumento da pesquisa. Participaram da pesquisa 300 sujeitos distribuídos entre os três locais de coleta de dados. Apenas dois questionários foram eliminados por estarem incompletos, totalizando assim 298 questionários válidos.

Para a realização da pesquisa de campo utilizou-se como instrumento um questionário estruturado, adaptado de Queiroz, Souza e Gouvinhas (2008) e Campolina et al. (2007), contendo questões fechadas de múltipla escolha subdividido em três blocos, contendo a primeira parte questões sociodemográficas e as duas seguintes questões relacionadas às variáveis e dimensões investigadas. Para as questões relacionadas com as variáveis do estudo os sujeitos indicavam sua escolha numa escala ordinal com amplitude de 1 a 5 , sendo 1 para o atributo menos importante e 5 para o mais importante. Para confirmar a validação do questionário, foi aplicado um pré-teste para identificar possíveis limitações na coleta de dados, para que fossem corrigidas as falhas e limitações do instrumento.

Os dados sociodemográficos foram analisados e apresentados de forma descritiva e para os dados relacionados às variáveis utilizou-se tratamento estatístico multivariado com análise das médias, desvio padrão e análise fatorial confirmatória. Buscouse nessa etapa da pesquisa verificar e confirmar se a forma como as variáveis foram agrupadas no modelo de estudo estavam de acordo com o agrupamento

Quadro 1 - Variáveis da pesquisa

\begin{tabular}{l|l|l|l}
\hline Constructo & $\begin{array}{l}\text { Dimensão } \\
\text { avaliada }\end{array}$ & Variáveis & Autores \\
\hline PRAXIS & $\begin{array}{l}\text { Escolha da } \\
\text { Loja }\end{array}$ & $\begin{array}{l}\text { Atendimento, entrega em domicilio, estacionamento, limpeza e organização, } \\
\text { produtos de padaria, prazo pagamento, promoção, tempo de espera nas filas, } \\
\text { preço, proximidade da residência, qualidade do açougue, qualidade da feira, } \\
\text { qualidade e variedade frios laticínios, rapidez nos caixas, variedade de produtos, } \\
\text { facilidade de encontrar produtos desejados }\end{array}$ & $\begin{array}{l}\text { Queiroz, } \\
\text { Gouza e } \\
(2008)\end{array}$ \\
\hline PRÁTICAS & $\begin{array}{l}\text { Serviços } \\
\text { Oferecidos }\end{array}$ & $\begin{array}{l}\text { Estacionamento, entrega em domicílio, promoção, limpeza da loja, sinalização da } \\
\text { loja, marcas próprias, propaganda, atendimento, prazo de pagamento, rapidez } \\
\text { nos caixas, empacotador, cartão fidelidade }\end{array}$ & $\begin{array}{l}\text { Campolina } \\
\text { et al. } \\
(2007)\end{array}$ \\
\hline
\end{tabular}

Fonte: os autores, 2012. 
feito após rotação da matriz dos principais componentes. A fim de testar a adequação da amostra para a análise fatorial utilizou-se o teste KMO ((KaiserMeyer-Olkin) que, de acordo com Corrar et al. (2009), permite avaliar se os dados coletados são adequados para a utilização da análise fatorial.

\section{Resultados}

\section{Caracterização dos sujeitos}

A pesquisa na íntegra identificou diversos dados demográficos dos participantes, porém para efeito desta análise, apenas alguns dados, considerados relevantes foram reportados. Verificou-se que 76,3\% dos participantes eram do gênero feminino e apenas $23,7 \%$ do sexo masculino. Desta feita percebe-se maior participação feminina nas compras de supermercados entre esses consumidores. Com relação à idade, percebeu-se que se distribuíram proporcionalmente aos dados demográficos da localidade, ficando com $26 \%$ de pessoas entre 25 e 34 anos, $33 \%$ de participantes com 35 a 44 anos e $17 \%$ de sujeitos com idade entre 45 e 54 anos. A participação de compradores com idade inferior a 25 ou superior a 54 foi pequena.

Com relação à instrução dos investigados 12,1\% tinham na época até o primeiro grau, $68,5 \%$ segundo grau e $12,8 \%$ desses sujeitos de baixa renda informaram possuir ou estar cursando o nível superior. Destaca-se que 1,3\% dos sujeitos se declarou não alfabetizado. Com relação à renda confirmou-se que os investigados que frequentam esse perfil de supermercado pertencem majoritariamente à classe de baixa renda, pois $24,2 \%$ dos sujeitos declarou ter renda inferior a $R \$ 510,00$ sendo que $43,3 \%$ dos entrevistados ganhava na época entre $\mathrm{R} \$ 511,00$ e $R \$ 1.020,00$ e $16 \%$ informou sua renda entre $R \$$ $1.021,00$ e $\mathrm{R} \$ 1.530,00$. Em contraponto com os dados relacionados à instrução e renda dos sujeitos verificou-se que $44 \%$ dos sujeitos gasta acima de 150 reais em compras, conforme pode ser verificado na Tabela 1.

Com relação ao tempo que esses sujeitos frequentam os supermercados foi possível verificar tratar-se de clientes fiéis, já que a maioria, ou seja $63,4 \%$, declarou frequentar a loja há mais de 2 anos e 19,5\% vem frequentando o supermercado entre 1 e 2 anos. Apenas $11,8 \%$ desses consumidores frequentam a
Tabela 1 - Gastos que os sujeitos efetuam por visita ao supermercado

\begin{tabular}{l|c|c}
\hline Gastos por visita & F & $\%$ \\
\hline até 50 reais & 68 & 22,8 \\
\hline entre 51 e 70 reais & 39 & 13,1 \\
\hline entre 71 e 150 reais & 38 & 12,8 \\
\hline entre 151 e 230 reais & 50 & 16,8 \\
\hline entre 231 e 300 reais & 43 & 14,4 \\
\hline acima de 300 reais & 37 & 12,4 \\
\hline não quis informar & 7 & 2,3 \\
\hline Total & 298 & 100,0 \\
\hline
\end{tabular}

Fonte: dados da pesquisa, 2012.

loja a menos de um ano. Quando questionados sobre sua frequência de visita ao supermercado o percentual mais elevado, com $32,9 \%$ declarou ir ao supermercado mensalmente, e 15,1 quinzenalmente, sendo possível perceber uma tendência em sentido oposto a Alwit e Donley (1997), quando estes afirmam que o consumidor de baixa renda tende a frequentar o supermercado várias vezes ao mês fazendo pequenas compras em cada visita. Por outro lado, uma parcela importante, com 17,4\% declara fazer compras no supermercado semanalmente.

\section{Análise das variáveis}

Analisando a média atribuída às variáveis pelos sujeitos entrevistados, verificou-se o grau de importância dos atributos que levam o indivíduo a escolher a loja (Tabela 2). Verificou-se que dentre as ações relacionadas com a praxis, ou seja, atividades estratégicas diárias que favorecem a sobrevivência da empresa, a variável com grau médio mais elevado para os sujeitos refere-se ao atendimento que alcançou um grau de 3,79 dentro de uma amplitude que variou de 1 a 5 .

Logo a seguir verificou-se a entrega em domicílio com grau médio de 2,92 como segunda variável importante na prática estratégica para influenciar esses consumidores a escolherem a loja. Vale destacar o valor elevado para o desvio padrão, tanto na variável atendimento como na entrega em domicílio com 1,54 e 2,06 respectivamente.

Com relação às práticas estratégicas relacionadas aos serviços oferecidos verificou-se a mesma 
tendência de escolha das atividades estratégicas oferecidas pelos supermercados, pois repetiram-se as duas variáveis com maior grau de importância para os sujeitos apenas invertendo a ordem, ou seja, em primeiro lugar observou-se a entrega em domicílio com grau 3,42 e em segundo o atendimento com grau 3,31 conforme pode ser verificado na Tabela 3.
Nestes casos o desvio padrão também manteve-se elevado com 1,9 e 1,5 respectivamente.

Para responder ao objetivo da investigação, as variáveis investigadas foram rotacionadas pelos principais componentes utilizando a rotação Varimax, analisadas as comunalidades, extraídas as variâncias pela análise dos principais componentes bem como

Tabela 2 - Grau médio de importância das ações estratégicas para Escolha da Loja

\begin{tabular}{|c|c|c|c|}
\hline Principais atividades & $\mathbf{N}$ & Média & Desvio Padrão \\
\hline Atendimento & 298 & 3,79 & 1,542 \\
\hline Entrega em domicilio & 298 & 2,92 & 2,069 \\
\hline Limpeza e organização & 298 & 1,98 & 1,716 \\
\hline Promoção & 298 & 1,26 & 1,251 \\
\hline Qualidade da feira & 298 & 1,10 & 1,348 \\
\hline Preço & 298 & 1,09 & 1,336 \\
\hline Proximidade da residência & 298 &, 58 & 1,295 \\
\hline Rapidez nos caixas & 298 & 42 & ,846 \\
\hline Produtos de padaria & 298 & ,35 & 1,070 \\
\hline Estacionamento & 298 & 27 & 961 \\
\hline Qualidade do açougue & 298 & ,23 & 817 \\
\hline Facilidade de encontrar produtos desejados & 298 & 13 & 680 \\
\hline Variedade de produtos & 298 &, 05 & ,314 \\
\hline Tempo de espera nas filas & 298 & 03 & 311 \\
\hline Prazo pagamento & 298 & 01 &, 174 \\
\hline Qualidade e variedade frios laticínios & 298 & 01 & 174 \\
\hline
\end{tabular}

Fonte: dados da pesquisa, 2012.

Tabela 3 - Grau médio de importância das práticas estratégicas nos serviços oferecidos

\begin{tabular}{l|c|c|c}
\hline Serviços oferecidos & N & Média & Desvio Padrão \\
\hline Entrega em domicilio & 298 & 3,42 & 1,939 \\
\hline Atendimento & 298 & 3,31 & 1,506 \\
\hline Limpeza da loja & 298 & 2,54 & 1,452 \\
\hline Promoção & 298 & 2,36 & 1,545 \\
\hline Rapidez nos caixas & 298 & 1,12 & 1,014 \\
\hline Estacionamento & 298 &, 68 & 1,480 \\
\hline Propaganda & 298 &, 28 &, 686 \\
\hline Sinalização da loja & 298 &, 19 &, 650 \\
\hline Prazo de pagamento & 298 &, 10 &, 563 \\
\hline Cartão fidelidade & 298 &, 03 &, 182 \\
\hline Marcas próprias & 298 &, 03 &, 271 \\
\hline Empacotador & 298 &, 00 &, 058 \\
\hline
\end{tabular}

Fonte: dados da pesquisa, 2012. 
construídas as matrizes dos principais componentes para cada dimensão. Como a análise multivariada resulta em inúmeras tabelas de grande importância para a análise, neste artigo são apresentados apenas os resultados principais que permitiram responder ao objetivo da pesquisa bem como confirmar se as variáveis eram comuns com as demais de suas respectivas dimensões. A partir da aplicação do teste Kaiser-Meyer-Olkin, constatou-se a adequação da amostra para a verificação das dimensões relacionadas à praxis e às práticas pois obtiveram valores próximos a $0,5(0,514$ e 0,574 respectivamente) e nível de significância zero que, de acordo com Hair et al. (2005) e Corrar et al. (2009), trata-se de um resultado satisfatório para a aplicação da análise fatorial.

$\mathrm{Na}$ análise fatorial para a dimensão Escolha da Loja a extração pelos principais componentes resultou em grau elevado de comunalidade para todas as variáveis desse grupo, ficando a maioria entre 0,5 e 0,9 indicando que o fator explicaria todas as variáveis desse grupo, porém a análise da matriz de componentes rotacionados pelo método Varimax verificou-se que a variável prazo de pagamento resultou isolada no último componente e a variável proximidade da residência ainda que apresentasse correlação com as variáveis produtos de padaria e variedade de produtos estas também apresentaram grau elevado com outros componentes com características mais convergentes. Considerando ainda que a variável proximidade da residência teria pouca relação com a forma como o praticante executaria a prática na organização (WHITTINGTON, 2006), optou-se então por sua exclusão e consequentemente uma nova análise fatorial foi realizada resultando em 6 componentes com $63 \%$ da variância explicada. A análise dessa nova matriz de componentes indicou a possibilidade de reagrupamento das variáveis considerando sua sinergia com outras variáveis bem como as cargas fatoriais significativas em outros componentes, optou-se assim por considerar apenas três dimensões para o construto Praxis, relacionadas com o "fazer a prática", influenciando dessa forma a escolha da loja pelo consumidor de baixa renda: 1) dimensão "Ações econômicas" que explicariam variáveis relacionadas ao custo do produto ; 2) dimensão "Ações no microambiente" para explicar as variáveis que facilitam o ato de comprar ; e 3) a dimensão "Ações nos produtos" explicando as variáveis que diferenciam e agregam valor aos produtos, conforme pode ser verificado no Quadro 2.

Finalmente na análise fatorial para a dimensão Serviços Oferecidos, relacionada às práticas estratégicas, a extração pelos principais componentes resultou, na maioria das variáveis, grau mediano de comunalidade entre as variáveis dessa dimensão, ficando entre 0,55 e 0,73 excetuando apenas a variável promoção que resultou em 0,37 indicando baixa comunalidade com as outras variáveis desse grupo. A análise dos componentes permitiu confirmar a dimensão Serviços Oferecidos explicando dessa forma todas as variáveis desse grupo. A análise da matriz de componentes rotacionados pelo método Varimax indicou a redução de fatores para 5 componentes com $60 \%$ da variância explicada, porém as variáveis dos componentes 4 e 5 foram reagrupadas nos fatores 2 e 3 já que também apresentaram carga fatorial nesses grupos. Dessa forma foi possível identificar três dimensões relacionadas ao construto "práticas": 1) Práticas comportamentais e procedurais, que explicariam as variáveis relacionadas com os serviços recebidos pelos clientes; 2) Práticas motivacionais e discursivas, que explicariam as variáveis relacionadas aos valores econômicos percebidos pelos consumidores; e 3) Práticas cognitivas, explicando as variáveis que proporcionam vantagens na percepção dos compradores, conforme pode ser verificado no Quadro 3.

Quadro 2 - Componentes da dimensão Práxis

\begin{tabular}{l|l|l|l}
\hline Componentes & Ações econômicas & Ações no micro-ambiente & Ações nos produtos \\
\hline Empresas & - Limpeza e organização & - Entrega em domicílio & - Produtos de padaria \\
& - Preço & - Estacionamento & - Qualidade do açougue \\
& - Rapidez nos caixas & - Tempo de espera nas filas & - Qualidade da feira \\
& - Promoção & - Atendimento & - Variedade de produtos \\
& & - Facilidade de encontrar produtos & - Qualidade e variedade frios laticínios \\
\hline
\end{tabular}

Fonte: elaborado pelos autores, 2012 
Quadro 3 - Componentes da dimensão Práticas (Serviços Oferecidos)

\begin{tabular}{l|l|l|l}
\hline Componentes & $\begin{array}{l}\text { Serviços recebidos } \\
\text { (Práticas comportamentais } \\
\text { e procedurais) }\end{array}$ & $\begin{array}{l}\text { Valores econômicos } \\
\text { (Práticas motivacionais } \\
\text { e discursivas) }\end{array}$ & $\begin{array}{l}\text { Vantagem percebida } \\
\text { (Práticas cognitivas) }\end{array}$ \\
\hline Variáveis & - Rapidez nos caixas & - Cartão fidelidade & - Empacotador \\
& - Limpeza da loja & - Marcas próprias & - Sinalização da loja \\
& - Atendimento & - Prazo de pagamento & - Entrega em domicilio \\
& - Estacionamento & - Propaganda & - Promoção \\
\hline
\end{tabular}

Fonte: dados da pesquisa, 2012.

\section{Conclusão}

Assim como negócios de grande volume são mais ambicionados, as pesquisas sobre estratégias em grandes redes parecem atrativas, porém o mercado das pequenas e médias empresas, assim como o de microempresários, têm a capacidade de suportar economias regionais e vêm demonstrando maior imunidade aos grandes solavancos da economia globalizada. Esses pequenos negócios atendem prioritariamente ao consumidor de baixa renda que isoladamente pode ser insignificante, porém quantitativamente movimenta recursos importantes. Entender esse ambiente de negócio, suas práticas estratégicas bem como a preferência de seus consumidores pode auxiliar no desenvolvimento, consolidação e crescimento de futuros empreendedores.

Os dados coletados nesta investigação permitiram não só verificar quais ações são mais valorizadas pelos consumidores de baixa renda como também aquelas que lhes têm pouca ou nenhuma importância, como, por exemplo, cartão fidelidade, marcas próprias e empacotador. Ainda que a pesquisa tenha sido conduzida com uma amostra por conveniência de acesso, os resultados mostram tendências de comportamento de consumo para o segmento de baixa renda. Os resultados confirmam mais uma vez a literatura quando mostram que muito do que se divulga informalmente sobre o comportamento do consumidor de baixa renda trata-se apenas de preconceito ou mitos.

A utilização do modelo conceitual da ECP com três construtos proposto por Whittington (2006) mostrou-se adequada, apresentando alguma dificuldade na determinação das variáveis independentes bem como na escassez de escalas validadas até o momento da pesquisa. Confirmaram-se com esta investigação os conceitos da Estratégia como Prática e sua aplicabilidade nas ações empreendidas pelos profissionais envolvidos no negócio de pequenos supermercados permitindo ainda contribuir com conceitos teóricos relacionados às dimensões da Praxis e da Prática. Contudo recomenda-se que novas pesquisas sejam conduzidas a fim de complementar o conhecimento especificamente sobre os Praticantes da estratégia em pequenos supermercados.

\section{Referências}

ALWITT, Linda F.; DONLEY, Thomas D. Retail stores in poor urban neighborhoods. Journal of Consumer Affairs. v. 31, n. 1, p.139, summer, 1997.

ANDERSON, Teresa. Exploding myths about Marketing to Ds and Es. Brand Strategy, v. 162, n.1, p.37, aug, 2002.

BORGES, Admir R. Marketing de varejo: as estratégias adotadas pelos supermercados de vizinhança para conquistar e fidelizar clientes. Dissertação (Mestrado) Universidade Federal de Santa Catarina, 2001.

CAMPOLINA, Angelo Salvatierra et al Decisões de Compra dos Clientes de Supermercados de Anápolis. Revista de Economia da UEG, Anápolis (GO), v. 3, n. 1, jan/jun, 2007.

CORRAR, Luiz J. et al. Análise multivariada: para os cursos de administração, ciências contábeis e economia. São Paulo: Atlas, 2009.

HAIR Jr., J.F.; ANDERSON, R.E.; TATHAM, R.L.; BLACK, W.C. Análise Multivariada de Dados. Porto Alegre: Bookman, 2005.

HAMMOND, Allen L. e PRAHALAD, C. K. Selling to the poor. Foreign Policy, v. 142, n.1, p.30, may/jun, 2004. 
HARCAR, Talha; KARA, Ali e KUCUKEMIROGLU, Orsay. Consumer's percebed value and buying behavior of store brands: and empirical investigation. The Business Review, Cambridge, v. 5, n. 2, p.55, Summer, 2006.

IBGE - INSTITUTO BRASILEIRO DE GEOGRAFIA E ESTATÍSTICA. SEI 2007. Disponível em http:ibge.gov. br/home/estítica/pesquisa/default.shtm. acesso em: 12.ago.2008.

JARZABKOWSKI, P. Strategy as practice: an activity-based approach. London: Sage Publications, 2005.

JARZABKOWSKI, P.. Strategic practices: An activity theory perspective on continuity and change. Journal of Management studies, v.40, n.1, p.23, 2003.

JARZABKOWSKI, P.; BALOGUN, J.; SEIDL, D. Strategizing: The challenges of a practice perspective. Human Relations, v.60, n.1, p. 5, 2007.

JARZABKOWSKI, P.; Strategy as practice: Recursiveness, adaptation and practices in-use. Organization Studies, v. 25, n. 4. p. 529, 2004.

JARZABKOWSKI, P.; WILSON, D. C. Actionable strategy knowledge: a practice perspective. European Management Journal, v. 25, n.5, p. 348, 2006.

JOHNSON, G.; LANGLEY, A.; MELIN, L; WHITTINGTON, R. Strategy as Practice: Research directions and resources. Cambridge: University Press, 2007.

JOHNSON, G.; MELIN, L.; WHITTINGTON, R. Micro Strategy and Strategizing: Towards an activity-based view. Journal of Management Studies, v. 40, n. 1, p. 3, 2003.

LEVY, Michael.; WEITZ, Barton A. Administração de Varejo. São Paulo: Atlas, 2000.

MACHADO, M.D.; QUEIROZ, T.R.; MARTINS, M.F. Mensuração da qualidade de serviço em empresas de fast food: Revista Gestão e Produção, v. 13 n.2, p.261, mai-ago, 2006.

MARIETTO, Márcio Luiz. Estratégia como Prática: um estudo das práticas da ação estratégica nas MPEs situadas em clusters comerciais competitivos. Dissertação, Mestrado em Administração, FACCAMP-SP, 2011.
MATTAR, Fauze. Pesquisa de Marketing. Edição compacta. São Paulo: Atlas, 2001.

MINTZBERG, Henry, AHLSTRAND, Bruce, LAMPEL, Joseph. Safári de estratégia: um roteiro pela selva do planejamento estratégico. Porto Alegre: Bookman, 2000.

MONTEIRO, Carlos Sérgio Melo do Rego; SILVA, Bruno Rodrigues; LADEIRA, Rodrigo. Estratégias no varejo de alimentos: um estudo com análise fatorial e de clusters. Revista Gestão e Planejamento, BA, v.9, n. 2, jul./dez. 2008.

NEUBUSER, M.E.; ZAMBERLAN, L. e SPAREMBERGER, A. A satisfação do consumidor de supermercado. Revista de Administração da URI (Universidade Regional Integrada do Alto Uruguai) , v. 3, n. 4, p. 41. 2004.

NOBREGA, K. C. Servant Organization: How Individual Behavior Can Be Expanded to a Business Approach. Anais POMS 20th Annual Conference, Orlando, Florida, 2009.

O POTI. Renda baixa predomina no RN. Caderno Economia. Jornal 0 Poti. Natal, 29.mai. 2005.

PARENTE, J.G.; BARKI, E; KATO, H.T. Estratégias de marketing para o varejo na baixa renda. Anais eletrônicos do 310 Enanpad, 2007.

PRAHALAD, C.K. e HAMEL, G. Competindo pelo Futuro. Rio de Janeiro: Campus, 2005.

PRAHALAD, C.K. e HAMMOND, A. Serving the World's Poor, Profitably. Harvard Business Review, v. 80, n. 9, p.48, sep, 2002.

QUEIROZ, T.S.; SOUZA, T. e GOUVINHAS, R.P. Estratégias de marketing como um diferencial na escolha do supermercado de bairro. RAM - Rev. Adm. Mackenzie, v.9, n.3, São Paulo, maio/jun. 2008.

SLACK, Nigel. Vantagem competitiva em manufatura. 2a. ed. São Paulo: Atlas, 2002.

VAN DE VEN, A. H.; JOHNSON, P. E. Knowledge for theory and practice. Academy of Management Review, v.31, n.4, p.802, 2006. 
VEJA. Ela empurra o crescimento. São Paulo: Revista VEJA, ano 41, n. 13, p. 84, 02/abr. 2008.

WHITTINGTON, R. Completing the practice turn in strategy research. Organization Studies, v. 27, n. 5, pp. 613-634, 2006.

WHITTINGTON, R. Strategy practice and strategy process: Family differences and the sociological eye. Organization Studies, v. 28, n. 10, p. 1575, 2007.

WILSON, D. C.; JARZABKOWSKI, P. Pensando e agindo estrategicamente: Novos desafios para a análise estratégica. RAE - Revista de Administração de Empresas, v. 44, n. 4, p. 11, 2004.

Recebido: 14/08/2012

Received: 08/14/2012

Aprovado: 19/11/2012

Approved: 11/19/2012 
